\title{
Interleukin 4 increases human synovial cell expression of VCAM-1 and T cell binding
}

Hironori Shimada, Katsumi Eguchi, Yukitaka Ueki, Munetoshi Nakashima, Izumi Yamashita, Yojiro Kawabe, Masahiro Sakai, Hiroaki Ida, Takahiko Aoyagi, Shigenobu Nagataki

\begin{abstract}
Objective-The effects were studied of interleukin 4 (IL-4) on T cell-synovial cell adhesion and on the expression of adhesion molecules on the surface of synovial fibroblast-like cells.

Methods-The adhesion of $\mathbf{T}$ cells toward the synovial cells were measured by ${ }^{51}$ chromium-labelled adhesion assay. The expression of adhesion molecules on synovial cells were analysed by flowcytometry. Results-Stimulation of synovial cells with IL-4 increased T cell-synovial cells adhesion in a time- and dose-dependent manner. IL-4 considerably enhanced the expression of VCAM-1 on the surface of synovial cells, but not the expression of ICAM-1 and ELAM-1. The combination of IL-1 $\beta$ and IL-4 had no effect on the expression of ICAM-1 or VCAM-1 on the surface of synovial cells. The increased adhesion of $T$ cells to IL-4 stimulated synovial cells was inhibited significantly by adding anti-VCAM-1 or anti-CD29 monoclonal antibody. Furthermore, antiVLA- $4 \alpha$ or the combination of anti-VLA$4 \alpha$ and anti-VCAM-1 antibodies blocked completely T-cell binding to IL-4 stimulated synovial cells.

Conclusions-These results suggest that the increased adhesion of $T$ cells to IL4-stimulated synovial cells is mediated by VLA-4/VCAM-1 pathway.
\end{abstract}

(Ann Rheum Dis 1994; 53: 601-607)

The inflammatory cells in the synovium and synovial fluid in rheumatoid arthritis (RA) are thought to pass through the vasculature from the peripheral blood. The mononuclear cells that are recruited continually to the synovium may engage in cellular interactions that lead to the proliferation of $\mathrm{T}$ cells, production of autoantibodies and secretion of proinflammatory mediators such as cytokines. ${ }^{1}$ The persistence of the synovitis leads to destruction of cartilage and bone. ${ }^{2}$ The cellular interactions among the infiltrating lymphoid cells, cells of the monocyte/macrophage series, synovial cells, vascular endothelial cells, and extracellular matrix may play an important role in the initiating and perpetuating autoimmune processes in the synovium of patients with RA. ${ }^{4}$

Adhesion molecules play a fundamental role in many diverse immunological functions, especially antigen presentation, recognition of target cells by affector cells, and migration and retention of mononuclear cells. Many interactions that are mediated by adhesion molecules and their ligands may also mediate signal transduction leading to cellular activation or proliferation. ${ }^{5}$

Recent interest in the synovium from RA patients has focused on the possible role of adhesion molecules. ${ }^{6-9}$ Vascular cell adhesion molecule 1 (VCAM-1) was originally identified on cytokine-treated endothelial cells. ${ }^{10}$ The ligand for VCAM-1 is the integrin very late antigen 4 (VLA-4), ${ }^{11}$ a heterodimer comprised of $\alpha 4$ - and $\beta 1$-chains, that is expressed on $\mathrm{T}$ cells and monocytes but not on neutrophils. ${ }^{12}$ VCAM-1 is now known to be present on dendritic cells. ${ }^{13}$ VCAM-1 is also implicated in CD3 dependent $T$ cell proliferation, in conjunction with VLA-4, ${ }^{14}$ and in $\mathrm{B}$ cell adherence to dendritic cells. ${ }^{15}$ Increased expression of VCAM-1 has been demonstrated in synovial tissue from RA patients. ${ }^{6-9} 15$ Recently, bright VCAM-1 staining has been detected on synovial intimal fibroblast-like cells, vascular wall cells outside the endothelial layer, scattered stromal cells with cytoplasmic processes, and cells resembling follicular dendritic reticulum cells in lymphoid aggregates with germinal centres. Some macrophages of the synovial intima show weak VCAM-1 staining. Endothelial cell staining was seen but it was consistently weaker than the staining of vascular wall cells. ${ }^{78}$

$\mathrm{T}$ cell interactions with fibroblast-like cells in RA synovium have been oberved by electron microscopy. Mitogen-activated peripheral blood $\mathrm{T}$ cells, but not fresh peripheral blood $\mathrm{T}$ cells, are reported to bind to synovial fibroblasts in vitro. ${ }^{17} \mathrm{We}$ demonstrated previously that stimulation of synovial fibroblasts with interferon $\gamma($ IFN- $\gamma)$ or interleukin $1 \beta$ (IL-1 $\beta$ ) considerably increases the binding of peripheral T cells to synovial fibroblasts. ${ }^{18}$

Interleukin 4 (IL-4), a $\mathrm{T}$ cell-derived lymphokine, was initially described as B cell stimulating factor $1\left(\mathrm{BSF}-1^{19}\right)$, but has been found to have a variety of effects on other haematopoietic and nonhaematopoietic cells. ${ }^{20-22}$ It has been reported that IL-4 induces the VCAM-1 expression on human umbilical endothelium cells (HUVEC). ${ }^{23}$

The present study was performed to further characterise the effect of IL-4 on synovial fibroblast-like cell activation by studying its action on T-cell adhesion and on the expression of adhesion molecules. 


\section{Materials and methods}

PATIENTS AND HEALTHY SUBJECTS

Synovium was provided by the Department of Orthopaedics, National Ureshino Hospital. It was obtained from six patients with RA [one man and five women, mean (SD) age 55 (12) years] at the time of surgery for total knee replacement. All of the patients fulfilled the American College of Rheumatology criteria for RA. ${ }^{24}$ In some of the experiments, synovial cells from patients with osteoarthritis (OA) were used. Peripheral blood samples were obtained from 12 healthy subjects [six men and six women, mean (SD) age 30 (5) years].

SEPARATION OF T CELLS FROM PERIPHERAL BLOOD

Mononuclear cells were isolated from heparinised blood of healthy donors by FicollConray gradient centrifugation (Daiichi Pharmaceutical Co, Tokyo, Japan). These cells were depleted of adherent cells by incubating the cell suspensions in Petri dishes (Falcon 3003, Becton Dickinson, Oxnard, CA) for two hours at $37^{\circ} \mathrm{C}$. A T-cell-enriched population was prepared from the non-adherent cells by rosetting with $5 \%$ sheep red blood cells (SRBC, Nippon Biotest Laboratory, Tokyo, Japan). In each experiment, $T$ cell purity was determined with anti-CD2, anti-CD20 and anti-MY4 monoclonal antibodies (Coulter Immunology, Hialeah, FL), which react, respectively, with mature $T$ cells, pan $B$ cells and monocytes. $\mathrm{T}$-cell rich populations were comprised of more than $95 \% \mathrm{~T}$ cells, less than $1 \% \mathrm{~B}$ cells and less than $1 \%$ monocytes.

\section{PREPARATION OF SYNOVIAL CELLS}

The method used to prepare synovial fibroblasts has been described elsewhere. ${ }^{25}$ In brief, the synovial tissue was trimmed of fat, minced with scissors, and then added to a mixture of collagenase (Sigma Chemical Co, St Louis, MO) and dispase (Godo Shusei Co, Tokyo, Japan). The tissue mixture was digested for 15 minutes during gentle stirring at $37^{\circ} \mathrm{C}$. The suspension was then passed through a nylon mesh and the resulting cells were allowed to adhere to Petri dishes (Falcon 3003) by culturing for 18 hours at $37^{\circ} \mathrm{C}$ in RPMI 1640 supplemented with $10 \%$ fetal bovine serum (FBS, GIBCO, Gland Island, NY). To eliminate nonadherent cells, the plated cells were washed extensively with phosphate-buffered saline solution (PBS). The synovial cells were then cultured with RPMI 1640 supplemented with $10 \% \mathrm{FBS}$ at $37^{\circ} \mathrm{C}$ in a humidified atmosphere at $5 \% \mathrm{CO}_{2}$ in air. The resulting synovial cells were used after their third or fourth passage for the following experiments.

SYNOVIAL CELL MONOLAYER ADHESION ASSAY The method used to study adhesion of $T$ cells to synovial cells has been described elsewhere. ${ }^{26}$ In brief, synovial cells $\left(2 \times 10^{4} /\right.$ well $)$ were cultured in quadruplicate in $96-$ well flat- bottomed microtitre plates (Costar, Cambridge, MA) for 24 hours with various concentrations or recombinant interleukin 4 (rIL-4, Ono Pharmaceutical Co, Osaka, Japan) or recombinant interleukin $1 \beta$ (rIL-1 $\beta$, Otsuka Pharmaceutical Co, Tokushima, Japan). After incubation, each synovial cell monolayer was washed thoroughly with RPMI 1640 containing 5\% FBS. T cells were radiolabelled with $\mathrm{Na}_{2}{ }^{51} \mathrm{Cr} \quad \mathrm{O}_{4} \quad$ (Amersham International, Amersham, UK) at $37^{\circ} \mathrm{C}$ for two hours with occasional shaking, then were washed three times with RPMI 1640 containing 5\% FBS. The washed cells were resuspended at $1 \times 10 \% \mathrm{ml}$ in RPMI 1640 supplemented with $10 \%$ FBS. Chromium-labelled $\mathrm{T}$ cells $\left(2 \times 10^{5} / 200 \mu \mathrm{l}\right)$ were added to the synovial cell monolayer; this mixture was incubated for two hours at $37^{\circ} \mathrm{C}$ in a humidified atmosphere at $5 \% \mathrm{CO}_{2}$ in air. The microtitre plates were then washed five times to remove nonadherent $\mathrm{T}$ cells. The adherent $\mathrm{T}$ cells were lysed by adding $200 \mu \mathrm{l}$ of a $1 \%$ solution of polyoxyethylene octylphenyl ether. The data were expressed as percentage bound $T$ cells, determined according to the following formula:

Percent bound $\mathrm{T}$ cells $=\frac{\mathrm{cpm} \text { in lysate }}{\mathrm{cpm} \text { in original } \mathrm{T} \text { cell suspension }} \times 100$ In some experiments, monoclonal antibodies to adhesion molecules were added to the synovial cell monolayer adhesion assay culture and incubated for two hours at $37^{\circ} \mathrm{C}$ in a humidified atmosphere at $5 \% \mathrm{CO}_{2}$ in air.

\section{MONOCLONAL ANTIBODIES}

The murine monoclonal antibody 25.3.1, a mouse IgG1 directed against the $\alpha$-chain (CD11a) of LFA-1, was purchased from Immunotech SA (Marseille, France). AntiCD29 (4B4), a mouse IgG1 directed against the $\beta$-chain of the integrin VLA, was a gift from Dr Chikao Morimoto, Division of Tumor Immunology, Dana-Faber Cancer Institute, Boston, MA. The monoclonal antibody HP $2 / 1$, a mouse IgG1 directed against the $\alpha 4$ subunit (CD49d) of VLA-4, was purchased from Immunotech SA. The monoclonal antibody $84 \mathrm{H} 10$, a mouse IgG1 directed against ICAM-1 (CD54), was also purchased from Immunotech SA. The monoclonal antibody BBA-1 is a mouse IgG specific for ELAM-1, and both BBA- 5 and BBA- 6 (mouse IgG1) bind VCAM-1. These monoclonal antibodies were purchased from Biotec $G$, Abingdon, Oxon, UK.

INDIRECT IMMUNOFLUORESCENCE METHOD The expression of adhesion molecules by synovial cells was examined by an indirect immunofluorescence technique. Synovial cells $\left(3 \times 10^{5} / 2 \mathrm{ml}\right)$ were cultured in 6 -well plates (Costar) with various amounts of rIL-4 at $37^{\circ} \mathrm{C}$ in humidified $5 \% \mathrm{CO}_{2}$ in air. After incubation, the cells were washed twice with PBS without calcium or magnesium and then incubated with $0.02 \%$ EDTA solution for six minutes at $4^{\circ} \mathrm{C}$. The synovial cells were detached from the plates using a rubber policeman and an 
autopipetter. The resulting cells were washed with ice-cold PBS containing 1\% FBS and $0.1 \% \mathrm{NaN}_{3}$, and resuspended to $1 \times 10^{6} / \mathrm{ml}$. To prevent nonspecific binding of $\mathrm{Fc}$ fragments to the Fe receptor on synovial cells, the cells were incubated with human gamma-globulin for 30 minutes at $4^{\circ} \mathrm{C}$. The cells were washed twice and then allowed to react with monoclonal antibodies for 30 minutes at $4^{\circ} \mathrm{C}$. After washing, FITC-conjugated affinity-purified goat IgG $\left.\mathrm{F}(\mathrm{ab})^{\prime}\right)_{2}$ anti-mouse Ig (Zymed, San Francisco, CA) was added to each sample. Cell number and mean fluorescence intensity were measured with a flow cytometer (FACScan, Becton Dickinson, Mountain View, CA). Mouse IgG (Tago Inc, Burlingame, CA) was used as a control. Forward and right angle scatter gates were set for synovial cells, and fluorescence signals were acquired using a log scale.

\section{STATISTICS}

Statistical analysis was performed using Student's $t$ test or the paired $t$ test, and any $\mathrm{p}<0.05$ was considered significant.

\section{Results}

EFFECTS OF IL-4 ON T-CELL BINDING TO

HUMAN SYNOVIAL CELLS

At first we investigated whether rIL-4 increases T-cell binding to synovial fibroblast-like cells. The kinetics of rIL-4-induced T-cell-synovial cell adhesion are shown in fig 1A. When synovial cells from patients with RA were cultured with $250 \mathrm{U} / \mathrm{ml}$ of rIL-4 for various time periods up to 96 hours, the percentage of $T$ cells that adhered to the synovial cells increased significantly within three hours of culture. This percentage reached a maximum at 24 hours of culture and was maintained through 96 hours of culture. As a result of this finding, $\mathrm{T}$-cell binding to synovial cells was determined in subsequent experiments at 24 hours of culture. The percentage of peripheral blood $\mathrm{T}$-cell binding to untreated synovial cells was $7 \pm 1 \%$.

Next, synovial cells were cultured with various amounts of rIL-4, and T-cell binding to synovial cells was detected at 24 hours of culture. Ten $\mathrm{U} / \mathrm{ml}$ of $\mathrm{rIL}-4$ enhanced significantly $\mathrm{T}$-cell binding to synovial cells (fig 1B). Maximum binding occurred with $50 \mathrm{U} / \mathrm{ml}$ of rIL-4 and was maintained up to $1000 \mathrm{U} / \mathrm{ml}$ of rIL-4. In addition, T-cell binding to synovial cells from two patients with OA was similar to that of patients with RA. To determine whether autologous $\mathrm{T}$ cells adhere to cells like allogeneic $\mathrm{T}$ cells, $\mathrm{T}$ cells were isolated from RA patients and normal individuals. There was no significant difference between autologous and allogeneic T-cell binding to rIL-4 treated synovial cells (data not shown). We therefore used allogeneic $T$ cells in the following experiments.

We then investigated whether IL4-stimulated $T$ cells bind more strongly to synovial cells pretreated with rIL-4. T cells isolated from peripheral blood were cultured
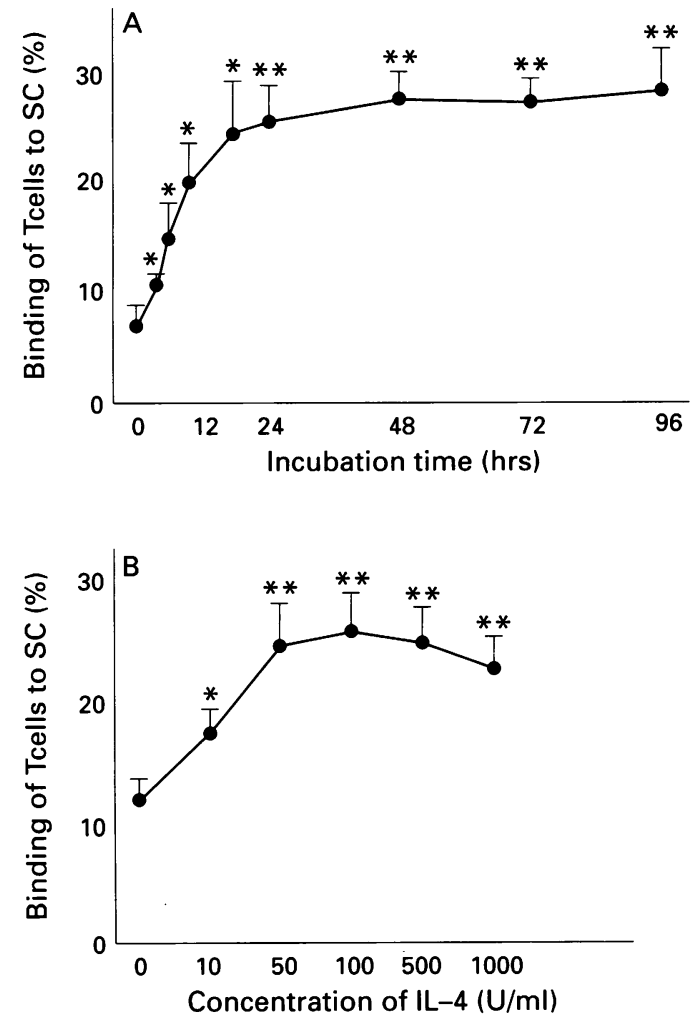

Figure 1 Effects of rIL-4 on T-cell adhesion to synovial fibroblast-like cells. (A) the kinetics of T-cell adhesion to rIL-4 treated synovial cells. Synovial cells were pretreated with $250 \mathrm{U} / \mathrm{ml}$ of $\mathrm{rIL}-4$ for 0 to 96 hours. After incubation, the synovial cells were washed and incubated with ${ }^{5 l} \mathrm{Cr}$ labelled T-cells for 2 hours. Percentage T-cell binding to synovial cells was determined as described in Materials and methods. Each point represents the mean of three individual experiments. Bars depict mean (SD).

${ }^{{ }} p<0.01 \mathrm{v}$ percentage $T$-cell binding to unstimulated synovial cells.

${ }_{*}^{*} p<0.001 \mathrm{v}$ percentage $T$-cell binding to unstimulated synovial cells; (B) T-cell adhesion to synovial cells pretreated with various concentrations of rIL-4. Synovial cells were cultured for 24 hours with 0 to $1000 \mathrm{U} / \mathrm{ml}$ of $r I L$ 4. The data are the mean (SD) percentage of three individual experiments. Bars depict mean (SD). ${ }^{*} p<0.01 \mathrm{v}$ percent $T$-cell binding to unstimulated synovial cells.

${ }_{\star \star *} p<0.001 \mathrm{v}$ percent $T$-cell binding to unstimulated synovial cells.

with or without rIL-4 for five hours. After incubation, the $\mathrm{T}$ cells were added to synovial cell monolayers pretreated or not with rIL-4. As shown in fig 2 , treatment of $\mathrm{T}$ cells with rIL4 did not increase $T$ cell adhesion to unstimulated synovial cells, and did not increase T-cell adhesion to IL-4-stimulated synovial cells. This finding demonstrated clearly that $\mathrm{T}$-cell binding to synovial cells is increased by pretreatment of synovial cells, but not T-cells, with IL-4.

EXPRESSION OF ADHESION MOLECULES ON SYNOVIAL CELLS PRETREATED WITH IL-4

The treatment of synovial cells with IL-4 increased the percentage of $\mathrm{T}$-cell binding to synovial cells. We tried to discover therefore which adhesion molecules on synovial cells mediate the increased T-cell binding to IL4-stimulated synovial cells. Synovial fibroblastlike cells were stimulated with $200 \mathrm{U} / \mathrm{ml}$ of rIL4 for various time periods. The surface expression of three adhesion molecules, ICAM- 


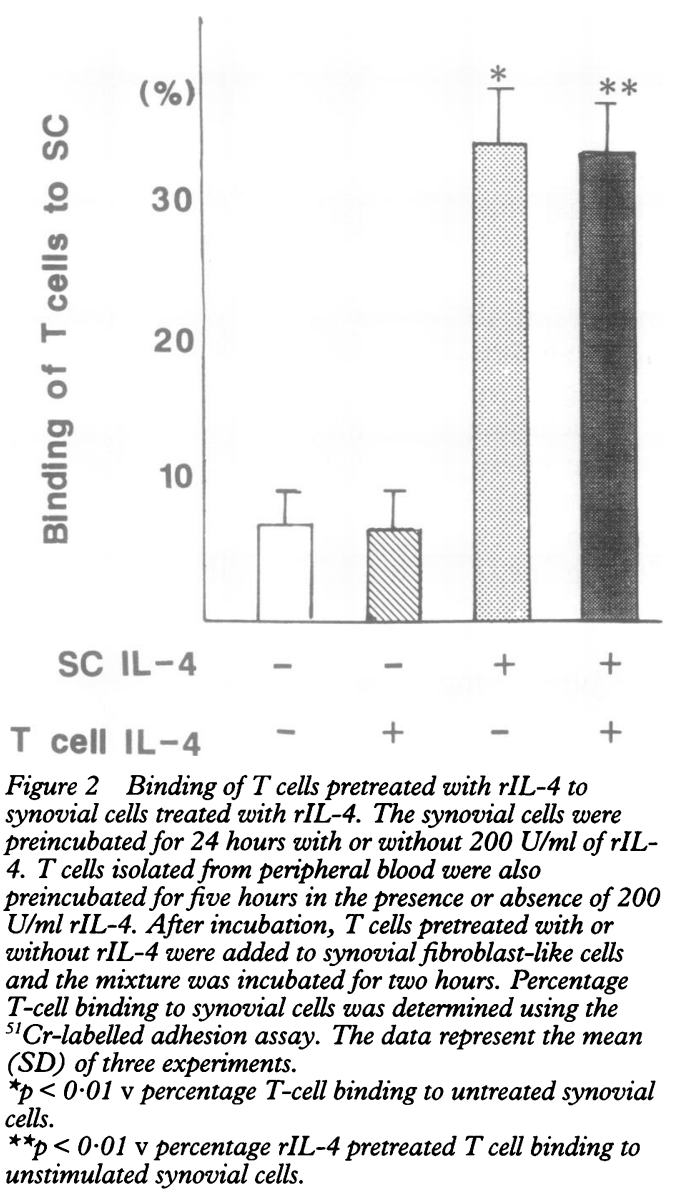

1, VCAM-1 and ELAM-1 was measured by flow cytometry. Unstimulated synovial fibroblast-like cells expressed constitutionally the ICAM-1 molecule, but not ELAM-1 molecule. A small percentage. of synovial fibroblast like cells usually expressed VCAM-1 on their surface. IL-4 enhanced significantly VCAM-1 expression by synovial cells at three hours of culture. Figure 3 shows a representative histogram of VCAM-1 expression on IL-4-stimulated synovial cells. The intensity of VCAM-1 expression on synovial cells stimulated by rIL-4 increased in a timedependent manner. Maximum expression was attained after eight hours of synovial cell stimulation with rIL-4 and was maintained for at least 36 hours. In contrast to VCAM-1, rIL-4 had no effect on the expression of either ICAM1 or ELAM-1 molecules (fig 4).

We then studied the dose-dependency of IL4 on the expression of adhesion molecules. Synovial cells were stimulated for 18 hours with various concentrations up to $1000 \mathrm{U} / \mathrm{ml}$ of rIL-4. The increased VCAM-1 expression was observed at the concentration of $1 \mathrm{U} / \mathrm{ml}$ rIL-4. Peak expression was attained at the concentration of $10 \mathrm{U} / \mathrm{ml}$ and was maintained at the concentration of $1000 \mathrm{U} / \mathrm{ml} \mathrm{rIl-4}$ (fig 5).

COMBINED IL-1 B AND IL-4 INDUCTION OF ICAM AND VCAM EXPRESSION ON SYNOVIAL CELLS We reported previously that stimulation of synovial cells with IL-1 $\beta$ increases ICAM-1 expression and $\mathrm{T}$ cell synovial cell adhesion. ${ }^{18}$
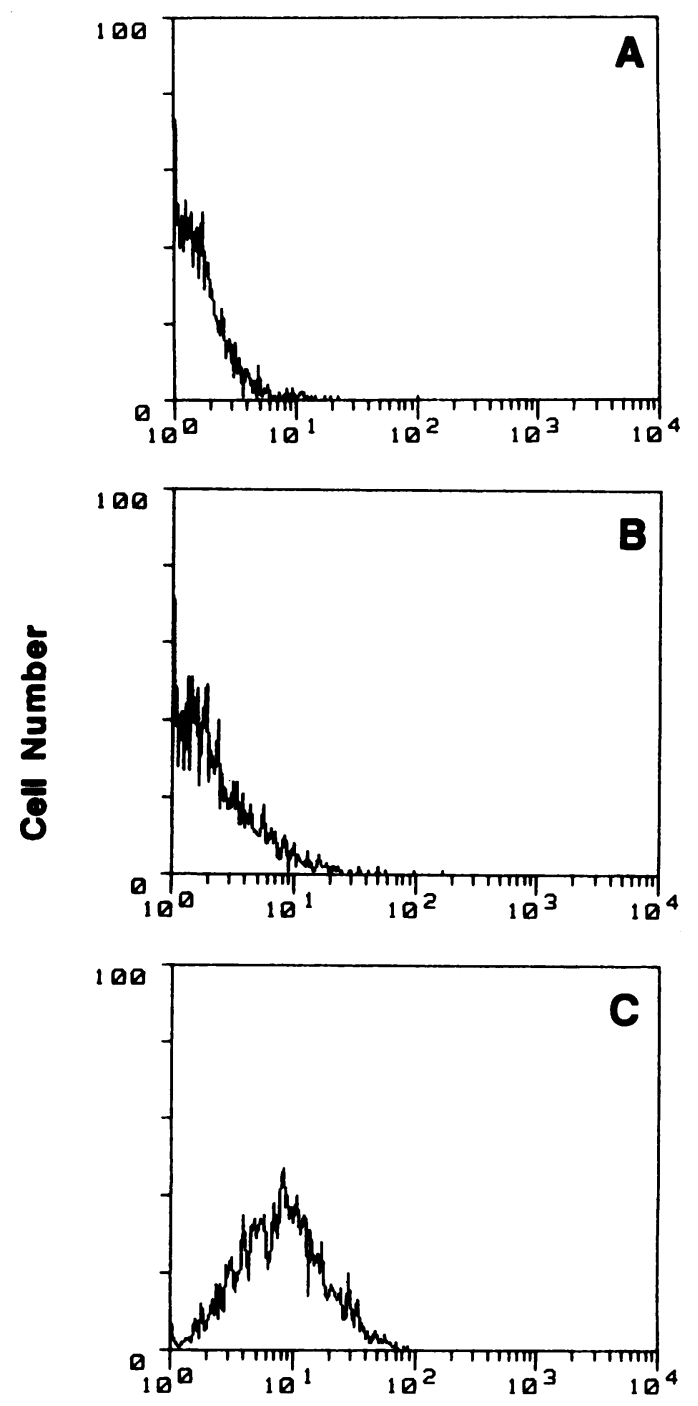

\section{Fluorescence Intensity}

Figure 3 IL-4 treatment of fibroblast-like cell increases VCAM-1 expression. Fibroblast-like cells were cultured for 24 hours with control medium alone or control medium containing IL-4. Cell number and fluorescence intensity were measured with FACScan. Mouse IgG control (A). VCAM1 expression on fibroblast-like cells cultured with control medium alone $(B)$ or control medium containing $I L-4(C)$.

The present study was therefore performed to investigate synergy between cytokines in the induction of adhesion molecule expression by human synovial cells. The synovial cells were stimulated with $10 \mathrm{U} / \mathrm{ml}$ of $\mathrm{rIL}-1 \beta$ in the presence or absence of rIL-4. As shown in table, rIL-1 $\beta$ increased the intensity of ICAM1 , but not VCAM-1 expression on synovial cells. Stimulation of synovial cells with rIL-1 did not enhance ICAM-1 expression by IL$1 \beta$-stimulated synovial cells. Furthermore, there was neither a synergistic nor additive effect on VCAM-1 expression by synovial cells when IL-1 $\beta$ and IL-4 were used in combination.

EFFECTS OF MONOCLONAL ANTIBODIES SPECIFIC FOR ADHESION MOLECULES ON T CELL-SYNOVIAL CELL ADHESION

Stimulation of human synovial fibroblast-like cells with IL-4 enhanced their expression of 


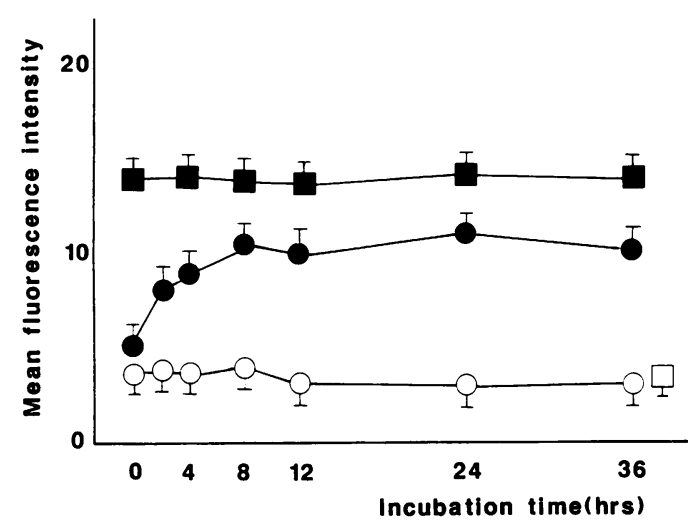

Figure 4 Expression of adhesion molecules on synovial cells stimulated with rIL-4. The synovial fibroblast-like cells were stimulated with $250 \mathrm{U} / \mathrm{ml}$ of $\mathrm{rIL}-4$ for various time periods. After incubation, the cells were collected using an autopipetter, and then treated with monoclonal antibodies to ICAM-1, VCAM-1 and ELAM-1. The mean fluorescence intensity was determined using a flow cytometer.

Background staining was determined using an isotypematched irrelevant monoclonal antibody. Mean fluorescence intensity is shown on the ordinate, and incubation time is shown on the abscissa. The data are the mean of three individual experiments.

$\longrightarrow$ expression of ICAM-1; $\longrightarrow$ expression of VCAM-1; $\bigcirc$ ○ expression of ELAM-1; $\square$ control.

VCAM-1 and increased their adherence to T-cells. We therefore tested the ability of antibodies against ICAM-1 (84H10), VCAM-1 (BBA6), VLA- $\beta$ (CD29) or VLA-4 $\alpha$ (HP 2/1) to inhibit $T$ cell-synovial cell adhesion. As shown in fig 6, stimulation of synovial cells with rIL-4 considerably increased the binding of $T$ cells to the synovial cells. AntiCD26 (4EL) and anti-LFA-1 $\alpha$ monoclonal antibodies did not inhibit $\mathrm{T}$ cell-synovial cell adhesion. Anti-ICAM-1 (84H10) monoclonal antibody reduced slightly $\mathrm{T}$-cell binding to synovial cells, but this effect was not significant. $\mathrm{T}$ cell-synovial cell adhesion was considerably blocked by anti-VCAM-1 and anti-CD29 monoclonal antibodies. The blocking of $T$ cellsynovial cell adhesion was shown to be about $75 \%$. Furthermore, either anti-VLA- $4 \alpha$ or combination of anti-VLA- $4 \alpha$ and anti-VLA- $\beta$

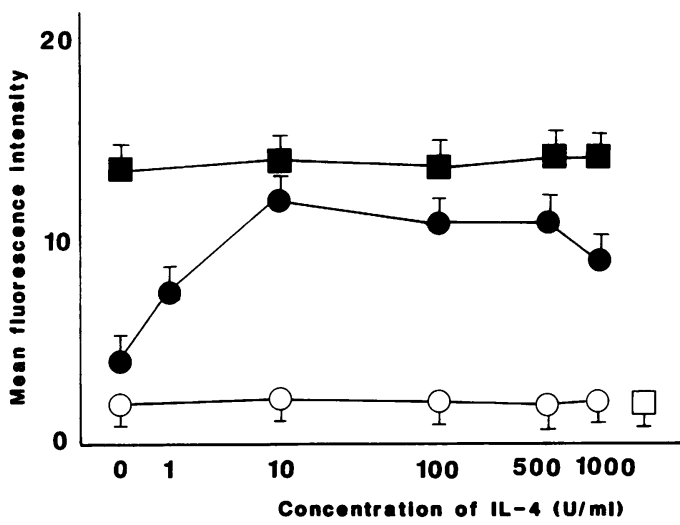

Figure 5 Expression of adhesion molecules on synovial cells treated with IL-4. Synovial fibroblast-like cells were incubated for 18 hours with various amounts of rIL-4. The expression of adhesion molecules on the synovial cells was analysed with a flow cytometer. Bars represent the mean (SD) of three individual experiments. Mean fluorescence intensity is shown on the ordinate, and the concentration of $r I L-4$ is shown on the abscissa.

$\longrightarrow$ expression of ICAM-1; $\longrightarrow$ expression of VCAM-1, $\bigcirc-0$ expression of $E L A M-1 ; \square$ control.
Combined effect of IL-1 $\beta$ and IL-4 on ICAM-1 and VCAM-1 expression by synovial fibroblast-like cells

\begin{tabular}{|c|c|c|c|}
\hline $\begin{array}{l}\text { Cytokine } \\
\text { rIL-1 }\end{array}$ & $r I L-4$ & \multicolumn{2}{|c|}{ Mean fluorescence intensity } \\
\hline - & - & $13 \cdot 5$ & $5 \cdot 2$ \\
\hline $10 \mathrm{U} / \mathrm{ml}$ & - & $39 \cdot 2$ & $5 \cdot 4$ \\
\hline- & $10 \mathrm{U} / \mathrm{ml}$ & $14 \cdot 3$ & $12 \cdot 0$ \\
\hline 10 & 10 & $37 \cdot 5$ & $10 \cdot 4$ \\
\hline 10 & 50 & $38 \cdot 5$ & $10 \cdot 1$ \\
\hline 10 & 100 & $42 \cdot 2$ & $10 \cdot 1$ \\
\hline 10 & 250 & $38 \cdot \overline{8}$ & $10 \cdot 5$ \\
\hline
\end{tabular}

(CD29) could block completely the binding of $\mathrm{T}$ cells to synovial cells.

\section{Discussion}

IL-4 is a T-cell-derived lymphokine with a variety of biological activities. ${ }^{20-22}$ This cytokine, originally described as a B cell stimulating factor 1 (BSF-1), can cause IgM-stimulated B cells to progress from the $\mathrm{Gl}$ phase of the cell cycle to the $S$ phase. ${ }^{19}$ IL-4 has subsequently been shown to stimulate B cell proliferation, ${ }^{19}$ $\mathrm{IgG}_{1}$ and IgE production, and class II MHC antigen expression on B cells. ${ }^{27}{ }^{28}$ IL- 4 effects on $\mathrm{T}$ cells include enhanced proliferation and increased survival. Receptors for IL-4 have been detected on a variety of haematopoietic cells, fibroblasts and epithelial cells. ${ }^{20-22}$ Although IL-4 may enhance lymphocyte function, this cytokine has complex and conflicting effects on several monocyte/ macrophage functions. IL-4 increases T-cell adhesion to human umbilical vein endothelial cells (HUVEC) and induces VCAM-1 expression by HUVEC. ${ }^{23} 29$ In our experiments, IL-4 increased rapidly T-cell adhesion to the synovial fibroblasts as it increased VCAM-1 expression on the surface of synovial fibroblasts.

Adhesion molecules are not only involved extensively in cell adhesion, but are also

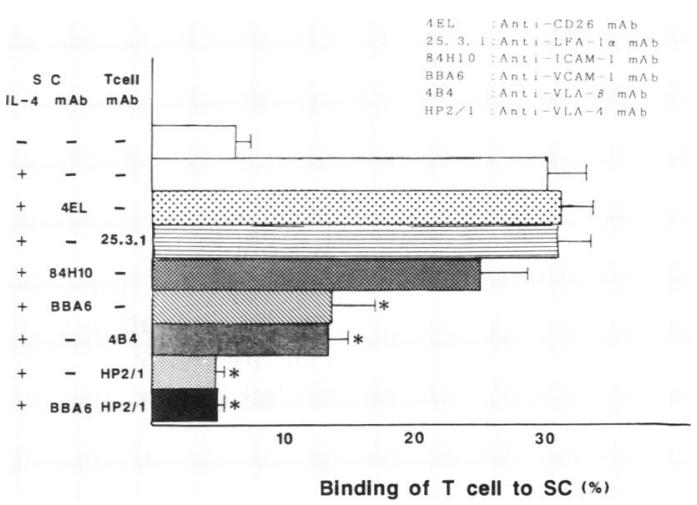

Figure 6 Inhibition of T-cell binding to IL-4-stimulated synovial cells by monoclonal antibodies to adhesion molecules. Synovial fibroblast-like cells was treated with or without rIL-4 (250 IU/ml) for 18 hours. The synovial cell monolayer adhesion assay was performed in the presence of

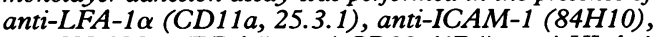
anti-VCAM-1 (BBA6), anti-CD29 (4B4), anti-VLA-4a (CD49d, HP 2/1) or anti-CD26 (4EL) as the control antibody. Chromium labelled $T$ cells were preincubated with monoclonal antibodies for 30 minutes at room temperature and added directly to the previously washed synovial cell monolayers which were preincubated with or without monoclonal antibodies. Experiments were performed in triplicate, and the results expressed as the mean (SD) of $T$-cell binding to human synovial cells.

${ }_{*}<0.001 \mathrm{v}$ percentage $T$-cell binding to untreated synovial cells. 
important in transduction of signals which activate cells or cause them to proliferate. ${ }^{30} 31$ The molecules involved in these interactions are divided into four major superfamilies based on their molecular characteristics: the integrin family, the immunoglobulin (Ig) supergene family, the selectin family and the H-CAM family (CD44). ${ }^{32}$ A wide variety of adhesiondependent interactions of lymphocytes, both in antigen-dependent and -independent processes, are mediated through interactions of LFA-1 (CD11a/CD18) with ICAM-1, and LFA-2 (CD2) with LFA-3. ${ }^{33}$ Those interactions include $T$-cell interactions with antigenpresenting cells, cytotoxic $\mathrm{T}$ cell-mediated killing, and lymphocyte binding to the endothelium. A second adhesion pathway involving VLA-4 binding to VCAM-1 and the CS-1 peptide from alternatively spliced fibronectin has been described. ${ }^{10} 1134$ VLA-4, which is comprised of the $\alpha 4$ (VLA-4 $\alpha$ ) and $\beta_{1}$ (CD29) subunits of the integrin family, is expressed on a variety of cell types, including lymphocytes, monocytes and eosinophils, but not neutrophils. ${ }^{12}$ These molecules may mediate lymphocyte adhesion to endothelial and antigenpresenting cells. ${ }^{35-37} \mathrm{~A}$ third pathway through sialyl $\mathrm{Le}^{\mathrm{x}}$ and sialyl $\mathrm{Le}^{\mathrm{a}}$ with ELAM-1 can mediate adhesion of neutrophils, monocytes, and lymphocytes to the endothelial cells. ${ }^{38} 39$

Using a range of double-labelling techniques, bright VCAM-1 staining has been detected on vascular wall cells outside on the endothelial layer. These cells may belong to a variety of nonendothelial resident populations such as smooth muscle cells and pericytes, and play an important role in the behaviour of lymphocytes subsequent to the initial phase of trans-endothelial migration. ${ }^{78}$ The bright VCAM-1 staining is shown on synovial intimal fibroblast-like cells, scattered stromal cells with cytoplasmic processes and cells resembling follicular dendritic reticulum cells in lymphoid aggregates with germinal centres. ${ }^{7} 814$

Large lymphocyte aggregates developing in rheumatoid synovial tissues mimic the development of lymphoid follicles in terms of the central accumulation of $\mathrm{B}$ cells and the presence of VCAM-1 -positive cells. ${ }^{8}$ The lymphoid follicles provide a specialised micro environment for the induction of antibody production, affinity maturation and memory $B$ cell formation. ${ }^{40}$ These adhesion molecules probably play a critical role in cellular interactions among B cells, $T$ cells and VCAM1-positive cells in the lymphoid follicles.

We studied adhesion molecule expression on cultured synovial cells, which are derived presumably from fibroblast-like cells. ICAM-1 was constitutively expressed by synovial cells but ELAM-1 was not expressed on resting synovial cells. The expression of ICAM-1 and ELAM- 1 on the cultured synovial cells did not enhance by addition of IL-4. It was reported that a small percentage of both RA- and OAderived synovial fibroblasts (3rd to 9th passage) expresses VCAM-1 on the surface. ${ }^{6}$ In our experiment, synovial cells from RA and OA synovium expressed constitutively VCAM1 on their surface, but the staining is weak.
We demonstrated that stimulation of synovial fibroblast with IL-4 increased T cellsynovial cell adhesion as it induced VCAM-1 expression by synovial fibroblast. The kinetics of increasing $\mathrm{T}$-cell adhesiveness and induction of VCAM-1 on IL-4-stimulated synovial cells were similar to those reported for IL4-stimulated HUVEC. However, IL-4 is shown to regulate the expression of adhesion molecules on HUVEC already activated by IL1 , TNF, or IFN- $\gamma \cdot{ }^{29}$ In our experiments, the combination of IL- 4 and IL- $1 \beta$ did not affect the expression of ICAM-1 and VCAM-1 on the surface of synovial fibroblast.

The present study demonstrated that IL-4 enhanced $\mathrm{T}$-cell binding to synovial fibroblast. Blocking studies demonstrated clearly that addition of the anti-VCAM-1 monoclonal antibody decreased weakly the adhesion of $\mathrm{T}$ cells to IL-4-stimulated synovial cells. To our surprise, anti-VLA-4 $\alpha$ monoclonal antibody blocked completely $\mathrm{T}$ cell binding to IL4-stimulated synovial cells. The CS-1 peptide in an alternatively spliced form of fibronectin, like VCAM-1, is a ligand for VLA. ${ }^{34}$ This molecule is expressed in synovial lining cells and on blood vessels in RA synovium. ${ }^{11}$ These results suggest that $\mathrm{T}$-cell adhesion to IL4-stimulated synovial cells is mediated through the VLA-4/fibronectin pathway and the VLA4/VCAM-1 pathway.

While much has been written regarding the role of the VLA-4/VCAM-1 pathway in recruiting lymphocytes into the synovium, ${ }^{36}$ less is known about its potential role in retaining cells and in the interactions between lymphocytes and synovial cells. We demonstrated previously that memory cells bearing CD45RO and CD29 antigens are more adherent to IL-1 $\beta$-stimulated synovial cells than are naive $T$ cells bearing the CD45RA antigen. ${ }^{18}$ The intensity of adhesion molecule expression on adherent $T$ cells is significantly higher than on nonadherent $\mathrm{T}$-cells. These results are in accordance with findings that the memory $\mathrm{T}$-cells have enhanced expression of adhesion molecules including LFA-1, CD2, VLA-4 and VLA-5 when compared with naive T-cells. ${ }^{37}$ The infiltrated $T$ cells, which are predominantly memory $\mathrm{T}$ cells, express an abundance of these adhesion molecules compared with peripheral blood T cells. ${ }^{41}$

Taken together, the present data suggest that $\mathrm{T}$-cell adhesion to synovial cells is mediated through the LFA-1/ICAM-1, VLA-4/VCAM1 , and VLA-4/fibronectin pathways. These interactions between lymphocytes and synovial cells may play an important role in activating and perpetuating immune responses or in retaining inflammatory cells in the $R A$ synovium.

\footnotetext{
1 Decker J L, Malone D G, Haraoui B, et al. Rheumatoid arthritis: evolving concepts of pathogenesis and treatment. Ann Intern Med 1984; 101: 810-24.

2 Dayer J-M, Krane S M, Russel R G G, Robinson D R Production of Collagenase and prostaglandins by isolated adherent rheumatoid synovial cells. Proc Nat Acad Sci USA 1976; 73: 945-9.

3 Harris E D Jr. Recent insights into the pathogenesis of the proliferative lesion in rheumatoid arthritis. Arthritis Rheum 1976; 19: 68-72.
} 
4 Iguchi T, Kurasaka M, Ziff M. Electron microscopic study of HLA-DR and monocyte/macrophage staining cells in the rheumatoid synovial membrane. Arthritis Rheum 1986; 29: 600-13.

5 Hemler M E, Elices M J, Parker C, Takada Y. Structure of the integrin VLA-4 and its cell-cell and cell-matrix adhesion functions. Immunol Rev 1990; 114: 45-65.

6 Koch A E, Burrows J C, Haines G K, Carlos T M, Harlan $\mathrm{J} M$, Leibovich $S \mathrm{~J}$. Immunolocalization of endothelia and leukocyte adhesion molecules in human rheumatoid and osteoarthritic synovial tissues. Lab Invest 1991; 64: 313-20.

7 Wilkinson L S, Edwards J C W, Poston R N, Haskard D $\mathrm{O}$. Expression of vascular cell adhesion molecule-1 in normal and inflamed synovium. Lab Invest 1993; 68: $82-8$.

8 Edwards J C W, Wilkinson L S, Speight P, Isenberg D A. Vascular cell adhesion molecule 1 and $\alpha 4$ and $\beta 1$ integrins in lymphocyte aggregates in Sjögren's syndrome and rheumatoid arthritis. Ann Rheum Dis 1993; 52: 806-11.
Morales-Ducret J, Wayner E, Elices M J, Alvaro-Gracia J $M$, Zvaifler N J, Firestein G S. $\alpha 4 / \beta 1$ integrin (VLA-4) ligands in arthritis: vascular cell adhesion molecule-1 expression in synovium and on fibroblast-like synoviocytes. $\mathcal{F}$ Immunol 1992; 149: 1424-31.

10 Osborn L, Hession C, Tizard R, et al. Direct expression cloning of vascular cell adhesion molecule 1 , a cytokineinduced endothelial protein that binds to lymphocytes. Cell 1989; 59: 1203-11.

11 Elices M J, Osborn L, Takada Y, et al. VCAM-1 on activated endothelium interacts with the leukocyte integrin VLA-4 at a site distinct from the VLA-4/fibronectin binding site. at a site distinct from

12 Walsh G M, Mermod J-J, Hartnell A, Kay A B, Wardlow A J. Human eosinophil, but not neutrophil, adherence to IL-1-stimulated human umbilical vascular endothelia cells in $\alpha 4 \beta 1$ (very late antigen-4) dependent. F Immunol 1991; 146: 3419-23.

13 Rice G E, Munro J M, Corless C, Bevilaqua M P. Vascular and nonvascular expression of INCAM-110. A target fo mononuclear leukocyte adhesion molecule in normal and inflamed human tissues. Am f Pathol 1991; 138: 385-93.

14 Burkly C, Jakubowski A, Newman B M, Rosa M D, ChiRosso G, Lobb R R. Signalling by vascular cell adhesion molecule-1 (VCAM-1) through VLA-4 promotes CD3 dependent T cell proliferation. Eur f Immunol 1991; 21: 2871-5.

15 Freedman A S, Munro J M, Rice G E, et al. Adhesion human $B$ cells to germinal centers in vitro involves VLA-4 and INCAM-110. Science 1990; 249: 1030-3.

16 Kobayashi I, Ziff $M$. Electron microscopic studies of lymphoid cells in the rheumatoid synovial membrane. Arthritis Rheum 1973; 16: 471-86.

17 Haynes B F, Grover B J, Whichard L P, et al. Synovia microenvironment-T cell interactions. Arthritis Rheum 1988; 31: 947-55.

18 Matsuoka N, Eguchi K, Kawakami A, et al. Phenotypic characteristics of $\mathrm{T}$ cells interacted with synovial cells. $\mathcal{F}$ Rheumatol 1991; 18: 1137-42.

19 Haward M, Farrar J, Hilfiker, et al. Identification of a T cellderived B cell growth factor distinct from interleukin 2 derived B cell growth factor dist

20 Ohara J, Paul W E. Receptors for B-cell stimulatory factor-1 expressed on cells of haematopoietic lineage. Nature $1987 ; 325$; $537-40$

21 Monroe J G, Halder S, Prystowsky M B, Lammie P. Lymphokine regulation of inflammatory processes: interleukin-4 stimulates fibroblast proliferation. Cli Immunol Immunopathol 1988; 49: 292-8.

22 Lowenthal J W, Castle B E, Christiansen J, et al. Expression of high affinity receptors for murine interleukin 4 (BSF-1) on hemopoietic and nonhemopoietic cells. $f$ Immunol 1988; 140: 456-64.
23 Thornhill M H, Kyan-Aung U, Haskard D O. IL-4 increases human endothelial cell adhesiveness for $\mathrm{T}$ cells but not for neutrophils. F Immunol 1990; 144: 3060-65.

24 Arnett F C, Edworthy S, Bloch D A, et al. The 1987 revised ARA criteria for rheumatoid arthritis. Arthritis Rheum 1987; 30: S17.

25 Wernick R M, Lipsky P E, Marban-Arcos E, Maliakkal J J, Edelbaum D, Ziff $M$. IgG and IgM rheumatoid factor synthesis in rheumatoid synovial membrane cell cultures. Arthritis Rheum 1985; 28: 742-52.

26 Kawakami A, Eguchi K, Ueki Y, et al. Effect of lobenzarit disodium on human endothelial cells. Arthritis Rheum 1991; 34: 296-303.

27 Noelle R, Krammer P H, Ohara J, Uhr J W, Vitetta E S Increased expression of Ia antigens on resting B cells: An additional role for B-cell growth factor. Proc Natl Acad Sci USA 1984; 81: 6149-53.

28 Roehm N W, Leibson H J, Zlotnik A, Kappler J, Marrack $\mathrm{P}$, Cambier J C. Interleukin-induced increase in Ia expression by normal mouse B cells. $f$ Exp Med 1984 160: $679-94$.

29 Thornhill M H, Haskard D O. IL-4 regulates endothelia cell activation by IL-1, Tumor necrosis factor, or IFN- $\gamma$. f Immunol 1990; 145: 865-72.

30 Van Seventer G A, Shimizu Y, Horgan K J, Shaw S. The LFA-1 ligand ICAM-1 provides an importan costimulattory signal for $\mathbf{T}$ cell receptor-mediated activation of resting $\mathrm{T}$ cells. F Immunol 1990; 144: 4579-86.

31 Tohma S, Hirohata S, Lipsky P E. The role of CD11a/ CD18-CD54 interactions in human T cell-dependent B cell activation. Immunol 1991; 146: 492-9.

32 Shimizu Y, Newman W, Tanaka Y, Shaw S. Lymphocyte interactions with endothelial cells. Immunol Today 1992; 13: $106-12$.

33 Pardi R, Inverardi L, Bender J R. Regulatory mechanisms in leukocyte adhesion: flexible receptors for sophisticated travellers. Immunol Today 1992; 13: 224-30

34 Wayner E A, Garcia-Pardo A, Hamphries M J, McDonald J A, Carter W G. Identification and characterization of the T lymphocyte adhesion receptor for an alternative cell
attachment domain (CS-1) in plasma fibronectin. $f$ Cell Biol 1989; 109: 1321-30.

35 Oppenheimer-Marks N, Davis L S, Tomkins Bogue D, Ramberg J, Lipsky P E. Differential utilisation of ICAM-1 and VCAM-1 during the adhesion and transendothelial migration of human T lymphocytes. F Immunol 1991; 147: migration

36 Van Dinther-Janssen A C H M, Horst E, Koopman G, et al. The VLA-4/VCAM-1 pathway is involved in lymphocyte adhesion to endothelium in rheumatoid synovium. F Immunol 1991; 147: 4207-10.

37 Shimizu Y, Van Seventer G A, Horgan K J, Shaw S. Roles of adhesion molecules in T-cell recognition: Fundamental similarities between four integrins on resting human $T$ cells (LFA-1, VLA-4, VLA-5, VLA-6) in expression, binding, and costimulation. Immunol Rev 1990; 114: 109-43.

38 Bevilacqua M P, Stengelin S, Gimbrone M A Jr, Seed B. Endothelial leukocyte adhesion molecule 1: an inducible receptor for neutrophils related to complement regulatory protein and and lectins. Science 1989; 243: 1160-5.

39 Springer T A, Lasky L A. Sticky sugars for selectins. Nature 1991; 349: 196-7.

40 Koopman G, Pals S T. Cellular interactions in the germinal centre: role of adhesion receptors and significance for the pathogenesis of AIDS and malignant lymphoma. Immuno Rev 1992; 126: 21-45.

41 Ueki Y, Eguchi $\mathrm{K}$, Shimada $\mathrm{H}$, et al. Increase in adhesion molecules on $\mathrm{CD} 4^{+}$cells and $\mathrm{CD4}^{+}$cell subsets in synovial fluid from patients with rheumatoid arthritis. $f$ Rheumatol 1994 (in press). 